International Journal of Current Advanced Research

ISSN: O: 2319-6475, ISSN: P: 2319 - 6505, Impact Factor: SJIF: 5.995

Available Online at www.journalijcar.org

Volume 6; Issue 4; April 2017; Page No. 3400-3404

DOI: http://dx.doi.org/10.24327/ijcar.2017.3404.0282

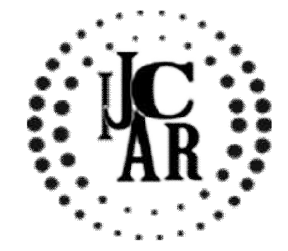

Research Article

\title{
IMMUNOGLOBULINS - PRESENT AND FUTURE
}

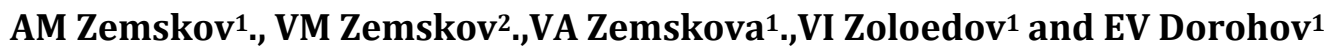

${ }^{1}$ N. N. Burdenko Voronezh State Medical University, Voronezh, Russia

${ }^{2}$ A.V. Vishnevsky Institute of Surgery, Moscow, Russia

\section{A R T I C L E I I N F O}

\section{Article History:}

Received $20^{\text {th }}$ January, 2017

Received in revised form $19^{\text {th }}$ February, 2017

Accepted $22^{\text {nd }}$ March, 2017

Published online $28^{\text {th }}$ April, 2017

\section{Key words:}

Immunoglobulins, Properties,

Application, Complications

\begin{abstract}
A B S T R A C T
The immunoglobulin preparations in addition to the utilitarian action on microorganisms and their metabolic products also possess a general, regulating, immunotropic, clinical and other effects, a certain probability of induction of adverse reactions and complications.
\end{abstract}

Copyright $₫ 2017$ AM Zemskov et al. This is an open access article distributed under the Creative Commons Attribution License, which permits unrestricted use, distribution, and reproduction in any medium, provided the original work is properly cited.

\section{INTRODUCTION}

Adaptive therapy based on the transferring of active immune factors, such as antibodies, with sera and immune globulins has had a recognized present and promising future. The hybridic technologies allowing to obtain monoclonal antibody of any specificity, provide a solution to a wide range of diagnostic, preventive and curative medical problems $[1,2,3]$.

\section{Classification of serum preparations}

All serum preparations are divided into two groups: heterologous, isolated from animal blood, and homologous, isolated from human blood. The first are obtained from the blood of large animals (mostly horses), subjected by intensive immunization (Grund immunization) by different vaccines and anatoxins. Usually they are antitoxic serumsantidiphtheria, antitetanus, antigangrenous, polyvalent antibotulinum, etc. The second are used for the prevention and treatment of hepatitis virus B, measles, botulism, tetanus, coccus and other infections. They are made from a mixture of donor or combined placental blood donor pool with low concentration of antibodies and they are introduced only intramuscularly, subcutaneously, or on skin. The immunoglobulins intended for intravenous use, are purified to remove aggregates. For practical use two versions of preparations are produced: pure antibodies - immune globulins obtained by the sorption on antigen sorbents and monoclonal - in hybridomas.

*Corresponding author: VM Zemskov

A.V. Vishnevsky Institute of Surgery, Moscow, Russia
The following preparations are manufactured in an industrial way: (1) serum - antitoxic (antitetanus, antibotulinic, antidiphtheria, antigangrenous), etc.; (2) anti-bacterial (antimeningococcal, antistreptococcal, antipneumococcal and others.); (3) immune globulins (Ig)-antivirus (antirabies, antitick-borne encephalitis, Crimean hemorrhagic fever and others.); (4) medical, of directed action are taken from the blood of volunteers vaccinated by various antitetanus, antistaphylococcal infections, antirabies, antivaricella, antiinfluenza, antihepatitis B virus preparations, etc.; (5) plasma and Ig taken from healthy donors; (6) diagnostic serum [4].

The effect of the serum preparations action is achieved by intravenous injection in a few minutes, intramuscularly - after several hours. The duration of homologous products action is 21-22 days, heterologous - not more than 10-12 days [5].

\section{Diagnostic specific immune serums}

They are used to determine the genus, species and typical belongings of micro-organisms or their antigens in reaction with known agglutinating, precipitating, hemolytic, fluorescent, antiglobulin, labeled radionuclides and other immune serums [6].

\section{Passive immunoprophylaxis of infections}

It is an introduction of serum preparations to possible contamination or directly after it, until the signs of the disease appear. To prevent hepatitis A virus, measles, whooping cough, meningitis, chicken pox, anthrax, gangrene, tetanus, botulism, staphylococcal lesions, flu, cytomegalovirus, herpes, etc. a normal human Ig, Citotekt, Octagam, Gabriglobin, Pentaglobin, specific horse serum and others are 
used. In some cases or critical situations, when the lack of the required drug is evident it is possible to introduce any Ig, because they contain more than 180-200 types of full and monovalent antiviral, antibacterial antibodies (against measles, polio, whooping cough, typhoid, paratyphoid, dysentery, pathogenic strains of E. coli, staphylococcus), antitoxins (diphtheria, staphylococcus, gangrenous), and others [7].

\section{Pathogenic specific serological infections therapy}

It implies the elimination of bacteria, neutralizing of toxins, viruses, the intensification of opsonic effect, antimicrobial protection in situations where the body is not able to provide independently an adequate resistance. Sometimes for this purpose the active-passive immunization that is a simultaneous administration of antigen and serum for a rapid formation of antiinfectious insusceptibility is used. Post infection serum therapy is included in the comprehensive treatment of severe acute, chronic, resistant to commonly used drugs diseases, specific Ig (antistaphylococcal, influenza, rabies, etc.), i. e. drugs realizing simultaneously etiotropicand pathogenetic - specific, targeted and nonspecific -of general action.Immunotherapy is commonly administered as soon as possible from the onset of the disease, in combination with other drugs - antivirus preparations, antibiotics, sulfonamides, corticosteroids, etc. [8].

\section{Immunoreplacement of humoral protective factors lack}

In some cases it means a life-long introduction of donors immunoglobulins in some forms of primary (common variable immunodeficiency - CVID), not often in secondary humoral immunodeficiency etc., to reduce the frequency and severity of bacterial lesions, preventing the development of irreversible complications and life-threatening infections. For the treatment a number of drugs with comparable efficacy and safety are used: intra-venous immunoglobulin (IVIg), immunoglobulin for subcutaneous administration (SCIg) normal human immunoglobulin 0,2-0,8 g dose / $\mathrm{kg}$ body weight at an interval of 2 weeks. It is also possible to introduce fresh frozen plasma at the rate of 20-80 ml per $1 \mathrm{~kg}$ of body weight, to carry out a blood transfusion. The criterion for achieving the saturation effect is the level of serum $\operatorname{IgG}:>$ $10 \mathrm{~g} / 1$ - good, 8-10 g / 1 - satisfactory, <5 g / 1 - an unsatisfactory result with an outlook to the subsequent transition to the regime of preventive maintenance immunotherapy [9].

In Russia, for replacement therapy the following standard IVIg are used: (1) Octagam (Octapharma Pharmazeutika Productions, GmbH, Austria); (2) Intraglobin (Biotest Pharma, GmbH, Germany); (3) Intratekt (Biotest Pharma, GmbH, Germany); (4) Pentaglobin (Biotest Pharma, Germany); (5) Gabriglobin (Moscow Gabrichevsky Research Institute of Epidemiology and Microbiology, The Russian Federation); (6) NeoCitotekt (Biotest Pharma, GmbH); (7) Gamimun H (Bayer Corporation, United States); (8) Humaglobin (Human Serum Production and Medicine Manufacturing Co Ltd, Hungary); (9) Gamunex (Talecris Biotherapeutics Inc, USA), (11) Immunoglobulin (Biohemi, Austria); (12), Sandoglobulin (Sandoz, Switzerland); (13) Venoglobulin (Pasteur Mere Konnot, France); (14) Immunovenin (NPO "Microgen" Russian Ministry of Health); (15) and other drugs of standard immunoglobulin $G[9,10$, 11$,$] .$

\section{Immunotrophic treatment of non-infectious diseases}

It implies the optimization of functions of immunity sections or separate factors with the help of the Ig. In the case of allergy gistoglobin (hystoglobulin) is used for the induction of antibodies formation against the main pathological mediator histamine. Antihistamine immunoglobulin provides the blocking of sensing receptors in the various organs and tissues, which causes desensitization. For the treatment of intestinal dysbiosis and intestinal dysfunctions a complex immunobiological preparation for enteral administration (CIP), comprising 3 main classes of immunoglobulins, protected from the action of digestive enzymes are used. In the syndrome of polyorganic failure and dysfunction as an adjunctive therapy Gabriglobin containing up to $95 \%$ of intact IgG monomers is indicated. In patients at risk (premature babies, infants in the period of artificial feeding, the elderly) the administration of a normal human immunoglobulin is rather effective. Sufficiently active in the treatment of idiopathic thrombocytopenic purpura and Kawasaki syndrome are Intraglobin and Sandoglobulin. An important component of the therapeutic aid in transplantation areIntraglobin and horse Limphoglobulin, containing anti-thymocyte antibodies. For the treatment of lymph-proliferative diseases advantageously applied antilymphocytic serum (ALS) and a ntilymphocytic $\gamma$-globulin (ALG), obtainable by heterological immunization of animals with their spleen cells, thoracic duct lymphocytes, periphery blood, and lymphatic nodes. The prospective study may be the creation of curative serums for key antigens of some malignant tumors. Hybridoma technologies helped to create vector proteins for targeted delivery of pharmaceuticals directly to target cells immunotoxins (a complex of anticancer Ig with botulinum toxin), Ig conjugated with radionuclides, chemotherapy, etc. [12].

\section{Regulation of immune homeostasis by antibodies and immunoglobulins}

It is known a phenomenon of antibodies selective suppression using IgG, especially IgM. Such inhibition is observed in the fetus and newborn under the influence of maternal antibodies that is used for the prevention of Rh-conflict with the help of anti-Rh IgG serum.

Antibodies are also produced to the idiotypic determinants of certain antigens - binding sites (Fab) of immunoglobulin molecules which are called anti-idiotypic antibodies. This phenomenon (according to the net theory by JerneRichter) is possible because the variable region of each immunoglobulin molecule is unique and can perform the function of an antigen to induce the formation of antiidiotypic antibodies, etc. to form long chains. This phenomena on the one hand provides a limitation and on the other hand a restoration of antibody against the causal epitope.

The accumulation in the body $\operatorname{IgA}$ and $\operatorname{IgM}$ simultaneously with the causal antigen appearance non-specifically stimulate the immune response. At the same time, IgG, on the contrary, has the capacity to inhibit the formation of specific antibodies in these conditions. It should be noted that the products of the catabolic destruction of these proteins also have a high biological activity. $\mathrm{F}(\mathrm{ab})_{2}$ fragments of homologous IgG are capable of enhancing the immunogenesis non-specifically. Fcfragment splitting products of immunoglobulins of various classes increase the vitality and migration of polymorph 
nuclear leukocytes, stimulate the presentation of antigen by A-cells, favor the activation of T-helper cells, and increase the immune response to thymus-dependent antigens [13].

\section{Immunotherapeutic guide}

It is a simultaneous correction of changes in various parameters of immune-hematologic, clinical and other states of patients. To illustrate this phenomenon a directed survey was conducted in which more than 200 patients with an exacerbation of chronic salpingoophoritis (ECSO) and purulent soft tissue infection (PSTI), divided into 8 randomized groups with 25-30 people in each, receiving a basic standard treatment for each nosoform and additional immune modulators - polyoxidonium (PO), sodium nucleinate (SN), Gabriglobin (GBG), its combinations with the correctors (Com) [5,13].

Before and after the complex treatment in 12-20 days the patients were subjected to be examined by conventional methods - routine laboratory hematologic, immune parameters were tested. From diagnostic material pathogenic staphylococci, E. coli, Klebsiella, Proteus, saprophytic flora were isolated and their associations registered the number of sterile samples. Clinical symptoms were recorded inflammatory foci, fever, regional lymphoadenopathy, pain syndromes, intoxication, etc. The comparison analysis was carried out using formalized methods with the following interpretation of the changes - reliable variations $>66 \%$ of indicators that were denoted as significant - 1 grade, $33-66 \%$ as average indicators - 2 grade and $<33 \%$ as insignificant - 3 grade [12]. The data obtained are presented in the table. immune parameters with the help of the coefficient of diagnostic value in different types of treatment. For example, Gabriglobin in patients with ECSO (FTI $\left.=\mathrm{NKc}_{3}^{+} \operatorname{IgM}_{3}^{+} \mathrm{IL}_{3}^{+}{ }_{3}\right)$ resulted in essential accumulation of the third grade of cytoxic natural killers, immunoglobulins of $\mathrm{M}$ class and proinflammatory interleukin 8 . The same preparation in patients with PSTI $\left(\mathrm{FTI}=\mathrm{PhI}_{3}^{+} \mathrm{TNRsp}_{3}^{+} \mathrm{MWM}_{3}^{-}\right)$provided a high activation degree of absorbing and metabolic phagocyte ability with the level reduction of average weight molecules. So, there is a differentiated set of signal targets of the same modulator in patients with different pathologies. On the other models of purulent inflammatory diseases - skin lesions, urinary organs pathologies, erysipelas, purulent lung destructions, osteomyelitis, complicated by burns, some septic conditions etc. with immune disorders is given an evident improving action of serum preparations (Gabriglobin, Normal human immunoglobulin) on various pathologically changed immune parameters $[10,12,13]$ (Fig.1)

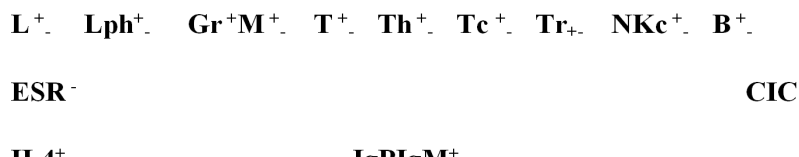

$\mathrm{II6}^{+}$

$\operatorname{IgA}^{+}$

IL8- IgG $^{+}$

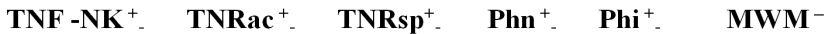

Figure 1 Influence of immunoglobulin preparations on laboratory parameters.

Table Clinical and laboratory efficiency of complex treatment and ECSO and PSTI as determined by the grade evaluation

\begin{tabular}{|c|c|c|c|c|c|c|c|c|c|c|}
\hline \multirow{3}{*}{ Treat-ment } & \multicolumn{8}{|c|}{ Indicators } & \multirow{3}{*}{ Sum of ranks/efficiency } & \multirow{3}{*}{$\begin{array}{l}\text { Formula of Targets } \\
\text { Immunocorrection }\end{array}$} \\
\hline & \multicolumn{2}{|c|}{ Hemato-logical } & \multicolumn{2}{|c|}{ Immune } & \multicolumn{2}{|c|}{ Bacterial } & \multicolumn{2}{|c|}{ Clinical } & & \\
\hline & $\mathbf{M}$ & $\mathbf{N}$ & M & $\mathbf{N}$ & $\mathbf{M}$ & $\mathbf{N}$ & $\mathbf{M}$ & $\mathbf{N}$ & & \\
\hline \multicolumn{11}{|c|}{ Exacerbation of chronic salpingoophoritis } \\
\hline $\mathrm{Bt}$ & 2 & 3 & 3 & 2 & 3 & 2 & 1 & 3 & 19/IV & $\mathrm{Tac}_{2}^{-} \mathrm{IgM}_{2}^{+} \mathrm{Th}_{2}^{-}$ \\
\hline Po & 1 & 2 & 2 & 2 & 3 & 1 & 2 & 2 & $15 / \mathrm{II}$ & $\operatorname{Tr}_{3}^{+} \operatorname{IgA}_{3}^{+} \mathrm{Tc}_{2}^{-}$ \\
\hline Gbg & 2 & 3 & 3 & 2 & 3 & 1 & 1 & 1 & $16 / \mathrm{III}$ & $\mathrm{NKc}_{3}^{+} \operatorname{IgM}_{3}^{+} \mathrm{IL}_{3}^{+}{ }_{3}$ \\
\hline Com & 1 & 2 & 3 & 3 & 3 & 1 & 1 & 2 & $13 / \mathrm{I}$ & $\mathrm{NKc}_{3}^{+} \mathrm{IgG}_{3}^{+} \mathrm{IL}_{4}^{+}{ }_{3}$ \\
\hline \multicolumn{11}{|c|}{ Purulent infection of soft tissues } \\
\hline $\mathrm{Bt}$ & 2 & 3 & 2 & 3 & 2 & 3 & 2 & 3 & 20/IV & $\mathrm{T}_{3}^{+} \mathrm{Th}_{3}^{+} \mathrm{PhI}_{3}^{+}$ \\
\hline $\mathrm{SN}$ & 2 & 2 & 2 & 2 & 2 & 2 & 2 & 1 & $15 / \mathrm{III}$ & $\mathrm{Tc}_{2}^{+} \mathrm{CIC}_{2}^{+} \mathrm{IL}_{3}^{+}$ \\
\hline Gbg & 1 & 2 & 2 & 1 & 2 & 2 & 1 & 1 & $12 / \mathrm{II}$ & $\mathrm{PhI}_{3}^{+} \mathrm{TNRsp}_{3}^{+} \mathrm{MWM}_{3}^{-}$ \\
\hline Com & 1 & 1 & 2 & 2 & 2 & 1 & 1 & 1 & $11 / \mathrm{I}$ & $\mathrm{IL6}_{3}^{+} \mathrm{TNRsp}_{3}^{+} \mathrm{Th}_{3}^{+}$ \\
\hline
\end{tabular}

Designation: M - mobile, N- normalizing effects, Bt - Basic treatment, I-IV - levels of efficiency the FTI - Formula of Targets Immunocorrection; Tac-T active Lph, Th- Thelper cells, Tr-T- resistant Lymphocytes, Tc- cytoxic Lymphocytes, CC- cytoxic cells, IL- interleukins, Ph I- phagocytic index, CIC- circulating immune complexes, TNRsp nitroblue tetrazolium reduction test spontaneous(generation of superoxide oxygen radical),MWM- medium-weight molecules. PO - polyoxidonium, SN - sodium nucleinate, Gbg - Gabriglobin, Com - its combinations with the correctors In FTI figures indicate the degree of changes of the patient's index from the level of a healthy person according to the following graduation -1- insufficient ( $<33 \%), 2$ - average- $(33-66 \%), 3-$ sufficient - $>66 \%)$, and the signs "+" or "-“ - indicate the rise or decline

The table shows that in different variants of complex patients treatment using combinations of monocorrectors and gabriglobins with these preparations, differentiated changes of clinical and laboratory parameters have been achieved. So, in the case of ECSO GBG provided maximal changes of clinical and bacteriological data, in PSTI - the same tests and hematological markers inflammation. In the cases of additional administration of Polyoxidonium modulation or Sodium nucleinate the effectiveness of the immunoglobulin preparation action has increased.

The reducing effectiveness of the differentiated immunotherapeutic guide in the case of ECSO was the following: $\quad \mathrm{Bt}+\mathrm{Gbg}+\mathrm{Po}>\mathrm{Bt}+\mathrm{Po}>\mathrm{Bt}+\mathrm{Gbg}>\quad \mathrm{Bt}$. In PSTI $\mathrm{Bt}+\mathrm{Gbg}+\mathrm{SN}>\mathrm{Bt}+\mathrm{Gbg}>\mathrm{Bt}+\mathrm{SN}>\mathrm{Bt}$. Some more information on FTI is given by the determination of key
Designation: IgP- immunglobulin preparations, Lleukocytes, Lph- lymphocytes, Gr - granulocytes, Mmonocytes, T - T-cells, Th - T-helpers, Tc- cytotoxic Lph, B B-cells, NKc - cytotoxic natural killers, ESR- erythrocyte sedimentation rate, IL- interleukins, TNF - tumor necrosis factor, IgM, IgA, IgG - immune globulins of classes M, A, G; MWM - medium - weight molecules, the CEC - circulating immune complexes, NK - Natural killer cells; TNRac and TNRsp - nitroblue tetrazolium reduction test is active and spontaneous (generation of superoxide oxygen radical), $\mathrm{PhI}$ phagocytic index, Phn - phagocytic number, “+”, “-“- - signs of stimulation and suppression of parameters values

According to the data of the figure 1 it is clear that the nature of the action IgP is modulating (stimulating / suppressing), depending on the baseline parameters and differentiated, that 
is directed on a wide range of laboratory indices - from hematological (white blood cells, lymphocytes, granulocytes, monocytes, ESR), to immune (main populations and subpopulations of lymphoid cells, natural killers, serum immune globulins of different classes); autoaggressive (average weight molecules, circulating immune complexes), absorbing and metabolic phagocyte activity, pro- and antiinflammatory cytokines as well as -clinical (these data are not shown in the figure).

\section{Adverse reactions and complications of serum products}

1. The introduction of the Ig preparations can cause headache, dizziness, migraine, nausea, vomiting, abdominal pain, diarrhea, increase / decrease of blood pressure, tachycardia, cyanosis, breathlessness, compression / pain in the chest. Not oftenhypotension, collapse, loss of consciousness, pyrexia, chills, sweating, myalgia, renal tubule necrosis.

2. It is possible the transfer of "injecting infections" (syphilis, malaria, hepatitis, HIV / AIDS) with native preparations. A temporary antibodies increase in the blood after administration of Ig may lead to false positive results of serological research methods. In the interval of a few hours / days can occur and disappear the signs of aseptic meningitis.

3. It is possible an induction of Ig allergic reactions up to anaphylactic shock. To avoid them a method of Bezredko is used: 30 minutes before intramuscular or intravenous administration, an intradermal serum sample preparation is made by the injection of $0.1 \mathrm{ml}$ of a 1: 100 drug and only in the absence of reaction the remaining dose is injected.The efficacy of antihistamines as preventive measures in these cases is low.

4. Introduction of the Ig for 1.5-3 months weakens the effectiveness of live-virus vaccines against - measles, rubella, mumps, polio, and varicella. The same occurs with the simultaneous administration of killed vaccines or anatoxins with antiserum.

5. The phenomena are described: the induction of endocrine disorders when injecting the boys under the age of 3 high doses of placental gamma globulin containing considerable concentrations of female sex hormones, up to fetus miscarriage in women who were treated under the age of 3 years, with large doses of serum preparations $(>3-6 \mathrm{ml} / \mathrm{kg}$ body weight).

6. It is theoretically possible in case of the body overloading with Ig as a result of the dehydrating the reduction of the detoxicational liver function, development of cachexia, inhibition of the active immunity formation against the causative agents in acute infectious processes, induction of toxic shocks as a result of the massive decay of microorganisms with the release of endotoxins, acute phase proteins and others.

7. Serum disease occurs in administration to body antitetanus, antiinfluenza, antidiphtheria, antibotulinic, antirabies, antigangrenous and other sera, antilymphocytic and gamma globulins and alien hormones (insulin, ACTH), vaccines, anatoxins, etc. The pathology is caused by the formation of immune complexes and their deposition in the walls of blood vessels, stimulating the complement system, the active factors of which are responsible for pathological clinical manifestations. After the first introduction of serum the symptoms appear on 7-15 days, after repeated use the reaction may occur immediately in some days, even a small amount of antigen is injected that is observed in the development of anaphylactic form of a serum disease.

\section{The clinical manifestations of serum disease}

Skin rash is polymorphous; it is almost a constant sign (90\%) of pathology. The fever usually comes on the eve (2 days) before the rash or simultaneously with it. It has a constant intermittent or subfebrile character. If it is maintained after the disappearance of other symptoms it indicates the chronization of the process. Articular syndrome of arthralgia resembling an acute articular rheumatic attack, accompanied by swelling, hyperemia, synovitis. It affects the large and small joints - knee, ankle, wrist, less intervertebral. There may be myalgias, especially along the nerve trunks, and polyneuritis. Lymphoadenopathy is a rapid increase of the regional lymph nodes, later in severe course the remote lymph nodes are involved in the process. The swelling of face, scrotum and other parts of the skin can occur. It is associated with a disorder of microcirculation; non-rarely combined with renal dysfunction (glomerulonephritis). Cardio-vascular system can also serve as a target of allergic reactions. Vasculitis can develop in various tissues, organs, skin, pancreas, muscles, having a hemorrhagic character. There are cases of cardiac dysfunction and deafness of its tones, low blood pressure, arrhythmia, changes in the electrocardiogram. There may be even myocarditis, pericarditis, and myocardial infarction. Lesions of the nervous system may be accompanied by headache excitation, encephalomyelitis, polyneuritis, most of the brachial plexus with the development of paresis and paralysis. In the blood at an early stage sometimes leukocytosis can develop, and at the top of the process - leucopenia with relative lymphocytosis and eosinophilia, thrombocytopenia, hypokomplementemia. There is a reduction of blood clotting, hypoglycemia.

According to the severity of the disease there is a mild form, which occurs in the form of single symptoms, itchy rashes, lymphoadenopathy; - with an extensive clinical picture with a permanent hypertrophy of lymph nodes, the changes in the cardiovascular system and heavy-with acute onset, generalized rash, hyperemia, lesions of the mucous membranes of the upper respiratory tract, shortness of breath, swelling of the face, hands, pain in muscles, joints for 3-5 weeks with a probability of chronic forms formation.

\section{General principles for the administration of passive immunization and immunotherapy}

1. Diabetes mellitus, chronic renal failure, pregnancy, lactation are contraindications for Ig administration.

2. In persons with systemic blood diseases, connective tissue disorders, glomerulonephritis etc. Ig treatment is carried out against the background of basic therapy.

3. The presence of primary immunodeficiency with complete inability to produce any $\mathrm{Ig}$ class is an exception to this method of treatment.

4. The account of possible complications is needed.

5. It is preferable to conduct a passive immunotherapy of the population who are in threat: children with immature immune systems, chronic debilitated 
patients, and elderly with a high degree of immune competence loss due to the depletion of lymphocytes during prolonged viral infections with a probability of bacterial complications development.

6. Traditionally the scheme of passive immunotherapy used with fractional interval for 1-5 days is undesirable, because the induction of antibody formation against the preparation with the neutralization of its effects is possible, the infusion of large doses of preparation but limited number of times -2-3 with an interval of 12-24- 48 hours is preferable.

7. A immunoglobulin injection is more rationally seemed in acute period of infectious disease, but not in remission or recovery.

\section{CONCLUSION}

The immunoglobulin preparations in addition to the utilitarian action on microorganisms and their metabolic products also possess a general, regulating, conductive, immunotropic, clinical and other effects with a certain probability of induction of adverse reactions and complications.

Practical application of serum preparations in medicine is carried out in immune diagnostics, passive immunization, specific pathogenic serological treatment of infections, immune replacement of humoral protective factors failure, immunotropic treatment of non-infectious diseases, regulation of immune homeostasis, immunotherapeutic clinical guide in immunodependent and immunoassociated pathological processes.

\section{References}

1. Petrov RV, Khaitov RM. Immunology and a New Generation of Vaccines. Moscow. Publishing House: GEOTAR-media. 2011. 711 p. Russia.

2. Zverev VV, Khaitov RM (Ed.).Vaccines and Vaccination.National Leadership. Quick Edition. Moscow. Publishing House: GEOTAR-media. 2014. 836 p. Russia.

3. Khaitov RM, Iljina NI (Ed.). Clinical Immunology and Allergology. Federal clinical guidelines. Moscow. 2015. 91 pp. Russia.
4. Zemskov AM, Zemskov VM, Karaulov AV, Mamchik NP, Evsegneeva IV, Malinovskaya VV, Kuprina NP, Zemskova VA. Immunology and Epidemiology of Infections.Educational Handbook for Medical Students. Voronezh-Moscow: Publishing House: Triada-X. 2015a. 375 p. Russia.

5. Novikov DK, Novikov PD. Clinical Immunopathology. Moscow. Publishing House: Medical Literature. 2009. 449 p. Russia.

6. Vorobjev AA (Ed.) Medical Microbiology, Virology and Immunology. Moscow. Publishing House: Medical Information Agency. 2008. 720 p. Russia.

7. Zemskov MV, Sokolov MI, Zemskov VM. Fundamentals of General Microbiology, Virology and Immunology. Mosow. Publishing House: Ear. 1977. 350 p. Rus- sia.

8. Tsarev VN (Ed.). Microbiology, Virology and Immunology.Textbook for High Schools. Moscow. Publishing House: GEOTAR-media. 2010. 5436 p. Russia.

9. Khaitov RM, Ataullakhanov RI.Immunotherapy.A guide for doctors. Moscow. Publishing House: GEOTAR-media. 2012. 669 p. Russia.

10. Zemskov AM, Esaulenko IE, Chereshnev VA, Zemskov VM, Suchkov SV, KozlovVA et al. Immunology. Electronic Textbook for Students of Medical Higher Education Institution and Faculties with Applications.Moscow. Publishing House: GEOTAR-media. 2016. 265 pages. Russia.

11. Pokrovsky VI (Ed.). Medical Microbiology. Textbook for High Schools. Moscow. Publishing House: GEOTAR-media. 2007. 765 p. Russia.

12. Zemskov AM, Zemskov VM, Zemskova VA, Zoloedov VI. Handbook of Clinical Immunologist "Theoretical, Practical and Applied Aspects of the Clinical Immunology at the Present Stage." Moscow. Publishing House: Triada-X. 2015. 704 p. Russia.

13. Zemskov AM, Zemskov VM, Chereshnev VA (Ed.). Encyclopedia of Immunology in 5 volumes. Moscow. Publishing House: Triada-X.2013. 1962 p. Russia.

\section{How to cite this article:}

AM Zemskov et al (2017) ' Immunoglobulins - Present And Future', International Journal of Current Advanced Research, 06(04), pp. 3400-3404.DOI: http://dx.doi.org/10.24327/ijcar.2017.3404.0282 